\title{
PIVKA-II Combined with Alpha-Fetoprotein for the Diagnostic Value of Hepatic Tumors in Children: A Multicenter, Prospective Observational Study
}

\section{Hongxiang Gao}

Shanghai Children's Medical Center, School of Medicine, Shanghai Jiao Tong University

https://orcid.org/0000-0002-4566-2214

\section{Chenjie Xie}

Shanghai Childrens Medical Center Affiliated to Shanghai Jiaotong University School of Medicine

\section{Jing Wang}

Shanghai Childrens Medical Center Affiliated to Shanghai Jiaotong University School of Medicine

Ji Ma

Shanghai Childrens Medical Center Affiliated to Shanghai Jiaotong University School of Medicine

\section{Shijian Liu}

Shanghai Childrens Medical Center Affiliated to Shanghai Jiaotong University School of Medicine

\section{Li Xie}

Shanghai Jiao Tong University School of Medicine

\section{Yijie Zheng}

wuxi diagnotics

\section{Rui Dong}

Children's Hospital of Fudan University

\section{Shan Wang}

Chongqing Medical University Affiliated Children's Hospital

\section{Yongjun Fang}

Children's Hospital of Nanjing Medical University

\section{Yurui Wu}

Qilu Children's Hospital of Shandong University

\section{Xianwei Zhang}

Children's Hospital Affiliated of Zhengzhou University: Zhengzhou Children's Hospital

\section{Xianying Lu}

Anhui Provincial Children's Hospital

\section{Yang Li}

Sun Yat-Sen Memorial Hospital

\section{Weisong Li}

First Affiliated Hospital of Anhui Medical University 


\section{Qiuhui Pan}

Shanghai Childrens Medical Center Affiliated to Shanghai Jiaotong University School of Medicine Min Xu

Shanghai Childrens Medical Center Affiliated to Shanghai Jiaotong University School of Medicine Song Gu (D731003249@shsmu.edu.cn )

Shanghai Children's Medical Center, School of Medicine, Shanghai Jiao Tong University

\section{Research}

Keywords: Children, Hepatic tumor, Alpha-fetoprotein, Protein induced by vitamin K antagonist-II

Posted Date: July 29th, 2021

DOI: https://doi.org/10.21203/rs.3.rs-726715/v1

License: (c) (i) This work is licensed under a Creative Commons Attribution 4.0 International License.

Read Full License 


\section{Abstract}

\section{Background:}

We aimed to investigate whether the protein induced by the vitamin $\mathrm{K}$ antagonist-II (PIVKA-II) combined with alpha-fetoprotein (AFP) can improve the diagnostic and differential diagnostic accuracy of childhood hepatic tumors.

\section{Methods:}

A multicenter prospective observational study was performed at nine regional institutions around China from October 1, 2018 to September 30, 2020, and a total of 257 eligible patients were enrolled. Children with confirmed hepatic masses were placed in the test group (Group T, $n=144$ ) and divided into the hepatoblastoma group (Group $\mathrm{T}_{\mathrm{HB}}, \mathrm{n}=98$ ) and the hemangioendothelioma group (Group $\mathrm{T}_{\mathrm{HE}}, \mathrm{n}=46$ ), and children with extrahepatic abdominal masses were placed in the control group (Group $C, n=113$ ). Peripheral blood was collected from each patient prior to surgery or chemotherapy. Receiver operating characteristic (ROC) curves and area under the curve (AUROC) were used to evaluate the diagnostic and differential diagnostic efficiency.

\section{Results:}

The mean levels of PIVKA-II and AFP were both significantly higher in Group T than in Group C $(P=0.001$, $P \otimes 0.001)$ and in Group $\mathrm{T}_{\mathrm{HB}}$ than in Group $\mathrm{T}_{\mathrm{HE}}(P=0.018, P=0.013)$. For the diagnosis performance, PIVKAII had a sensitivity of $86.7 \%$ and a specificity of $81.3 \%$ at a cutoff of $32.6 \mathrm{mAU} / \mathrm{ml}$ vs. $84.1 \%$ and $81.8 \%$ for AFP at a cutoff of $120 \mathrm{ng} / \mathrm{ml}$ (AUROC $0.867 \mathrm{vs.} 0.857$, respectively). The combination of PIVKA-II and AFP had higher sensitivity (88.5\%), specificity (84.7\%) and AUROC (0.891) than PIVKA-II or AFP alone. The differential diagnostic value of PIVKA-II and AFP in differentiating hepatoblastoma from hemangioendothelioma was further assessed. PIVKA-II had a sensitivity of $71.7 \%$ and a specificity of $88.7 \%$ at a cutoff of $47.1 \mathrm{mAU} / \mathrm{ml}$, and there was $63.0 \%$ and $78.6 \%$ of AFP at a cutoff of $560 \mathrm{ng} / \mathrm{ml}$ (AUROC 0.876 vs. 0.743 , respectively). The combined markers also showed a higher sensitivity $(72.7 \%)$, a higher specificity $(91.8 \%)$ and a higher AUROC (0.895) than PIVKA-II or AFP alone.

\section{Conclusions:}

The serum level of PIVKA-II was significantly higher in children with hepatic tumors, especially those with malignant tumors. PIVKA-II had superior sensitivity and specificity in the diagnosis of childhood hepatic tumors. The combination of PIVKA-II and AFP further increased the diagnostic performance.

Trial registration: Clinical Trials, NCT03645655. Registered 20 August 2018, https://www.clinicaltrials.gov/ct2/show/NCT03645655

\section{Background}


Although hepatic tumors rarely occur during childhood, they are associated with significantly higher morbidity and mortality in affected patients. Hepatoblastoma (HB) is the most common malignant hepatic tumor in children under the age of 3 years (1), and comprise approximately $5 \%$ of the total neoplasms of various types occurring in young children(2). The clinical features of HB are nonspecific but include the presence of an upper abdominal mass, loss of appetite, weight loss, anemia, jaundice, and ascites, all of which can seriously endanger the lives and health of children.

Hemangioendothelioma (HE) is the most common hepatic vascular tumor in infants less than 6 months of age, with a prevalence of $1 \%$ (3). Most patients with HE present with an asymptomatic abdominal mass and hepatomegaly, but these tumors may be associated with high-output cardiac failure due to the presence of arteriovenous shunts within the tumor.

Monitoring and early diagnosis play a vital role in the treatment of childhood hepatic tumors. In some clinical practices, ultrasound and contrast-enhanced computed tomography (CECT) are used as the primary modalities for the evaluation of palpable abdominal masses and the screening of hepatic masses $(4,5)$.

Although alpha-fetoprotein (AFP) has been recognized as a biomarker of hepatic tumors (6), it is not always elevated in all hepatic tumor cases. Elevated AFP levels alone are not sufficient for the diagnosis of hepatic tumors due to the physiological elevation seen in normal infants during the first 2 months and because of their association with other primary tumors (7).

The protein induced by the vitamin $\mathrm{K}$ antagonist-II (PIVKA-II) is also known as des-y-carboxyprothrombin (DCP) or carboxy prothrombin and is an abnormal form of prothrombin induced by the absence of vitamin $\mathrm{K}$ or antagonist-II(8). Motohara, K reported PIVKA-II levels were highly elevated in all three hepatoblastoma patients in 1987; plasma PIVKA-II might be useful as a new marker of hepatoblastoma (9).

Elevation of PIVKA-II, due to an excess production by tumor cells, has been shown to be associated with hepatocellular carcinoma $(\mathrm{HCC})(8,10,11)$. Many studies have demonstrated the clinical value of PIVKAII for HCC surveillance, and PIVKA-II has been recommended by the guidelines of the Japan Society of Hepatology (JSH) (12).

Theoretically, AFP and PIVKA-II are independently produced by tumors and are not correlated with one another. The diagnostic accuracy was better when using a combination of the biomarkers, AFP and PIVKA-II, compared to each marker alone for detecting HCC and early HCC in cirrhotic patients (13-15). Measurement of both PIVKA-II and AFP levels may yield useful information on the treatment response and prognosis in HCC patients $(16,17)$.

Given their application in HCC, we intend to investigate whether PIVKA-II combined with AFP can also improve the diagnostic and differential diagnostic accuracy of childhood hepatic tumors. 


\section{Methods}

\section{Study design}

This is a multicenter prospective observational study sponsored by the Shanghai Children's Medical Center and joined by nine regional institutions around China, including the Children's Hospital of Fudan University, the Children's Hospital of Chongqing Medical University, the Children's Hospital of Nanjing Medical University, the Qilu Children's Hospital of Shandong University, the Children's Hospital Affiliated to Zhengzhou University, the Anhui Provincial Children's Hospital, the Sun Yat-Sen Memorial Hospital, the Sun Yat-Sen University and the First Affiliated Hospital of Anhui Medical University. The study was conducted in accordance with the Declaration of Helsinki, and all participating centers obtained the relevant Institute Review Board ethics committee approval before patient enrollment. The study was registered in http://register.clinicaltrials.gov as NCT03645655.

\section{Eligible population}

Children (age $\leq 144$ months) first diagnosed with an abdominal mass in the pediatric general surgery inpatient department from October 1, 2018 to September 30, 2020 were consecutively enrolled in this study. The clinical diagnoses and differential diagnoses were based on contrast-enhanced computed tomography (CECT), histopathology, or both according to the International Childhood Liver Tumors Strategy Group (SIOPEL) protocols (18). A cavitation ultrasonic surgical aspirator (Soering $\mathrm{GmbH}$ ) was used for tumor biopsies and resections, which was safe and reliable. Children confirmed to have a hepatic mass were placed in the testing group (Group T) and were further divided into the hepatoblastoma group (Group $\mathrm{T}_{\mathrm{HB}}$ ) and the hemangioendothelioma group (Group $\mathrm{T}_{\mathrm{HE}}$ ); the other children confirmed to have an extrahepatic abdominal mass were placed in the control group (Group C). Informed consent was obtained from each child's legal guardian. Children with extra-abdominal tumors, ongoing vitamin $\mathrm{K}$ or warfarin treatment or lacking informed consent were excluded from this study.

\section{Laboratory measurements}

Peripheral blood was collected from each patient prior to any treatment (surgery and/or chemotherapy). Blood samples were centrifuged, and serum was aliquoted and stored at $-80^{\circ} \mathrm{C}$. All serum samples were tested in a single center to decrease the possibility of bias. Serum levels of AFP and PIVKAII were determined by a chemiluminescence enzyme immunoassay (CLEIA) (ARCHITECH 2000, Abbott Laboratory, US) using an enzyme-linked immunosorbent assay kit (Abbott Laboratory, US) per the manufacturer's instructions. All samples were analyzed in duplicate.

\section{Sample size calculation}

A sample size calculation was performed using PASS 15.0 (Power Analysis and Sample Size software, NCSS, Kaysville, UT, US) using the log-rank test. The planned sample size was determined after assuming the use of a 2-sided log-rank test with a type I error rate of 0.05 and a statistical power of $90 \%$. A dropout 
rate of up to $20 \%$ was factored into the computations. Ninety-three patients in each group were asked to participate in this study.

\section{Statistical analysis}

Student's t test (or Wilcoxon test) was used to compare the continuous variables, and the chi-square test (or Fisher's exact test) was used for the categorical variables. The average tumor marker levels were compared between Group $T$ and Group $C$ and between Group $T_{H B}$ and Group $T_{H E}$. Receiver operating characteristic curves (ROCs) and area under the ROC curve (AUROC) were used to assess the diagnostic and differential diagnostic efficiencies of PIVKA-II, AFP and the combination of the two tumor markers. A two-sided $P$ value less than 0.05 was considered statistically significant. All statistical analyses were carried out with SPSS version 20.0 (SPSS Inc., an IBM Company, Chicago, IL, US).

\section{Results}

\section{Patient characteristics}

A total of 257 eligible patients were enrolled in this study from October 1, 2018, to September 30, 2020. Table 1 shows the demographics of the participants. A total of 144 patients (mean age $24.4 \pm 28.5$ months) were confirmed to have hepatic masses (Group T), 98 patients (mean age $28.4 \pm 31.6$ months) were diagnosed with hepatoblastoma (Group $\mathrm{T}_{\mathrm{HB}}$ ), 46 patients (mean age $16.0 \pm 18.2$ months) were diagnosed with hemangioendothelioma (Group $\mathrm{T}_{\mathrm{HE}}$ ), and the other 113 patients (mean age $35.8 \pm 28.9$ months) were confirmed to have extrahepatic abdominal masses (Group $C$ ). There were no significant differences in age $(P=0.156)$, sex $(P=0.159)$, aspartate amino transferase (AST, $P=0.262)$, alanine amino transferase (ALT, $P=0.442$ ), gamma-glutamyl transpeptidase (GGT, $P=0.924$ ), total protein (TP, $P$ $=0.604$ ), albumin (ALB, $P=0.083$ ) or total bilirubin (TBIL, $P=0.897$ ) between Group T and Group C. Patients in Group $\mathrm{T}_{\mathrm{HE}}$ were younger than Group $\mathrm{T}_{\mathrm{HB}}(P=0.014)$; except for AST $(P=0.035)$, there were no significant differences in sex $(\mathrm{P}=0.075)$, ALT $(P=0.218)$, GGT $(P=0.779)$, TP $(P=0.564)$, ALB $(P=0.378)$, or TBIL $(P=0.092)$ between Group $\mathrm{T}_{\mathrm{HB}}$ and Group $\mathrm{T}_{\mathrm{HE}}$. 
Table 1

Baseline characteristics of patients

\begin{tabular}{|c|c|c|c|c|c|c|}
\hline & Group T & Group C & $P$ & Group $T_{H B}$ & Group $T_{\mathrm{HE}}$ & $P$ \\
\hline $\begin{array}{l}\text { Sample } \\
\text { size }\end{array}$ & 144 & 113 & & 98 & 46 & \\
\hline $\begin{array}{l}\text { Age } \\
\text { (Month) }\end{array}$ & $24.4 \pm 28.5$ & $35.8 \pm 28.9$ & 0.156 & $28.4 \pm 31.6$ & $16.0 \pm 18.2$ & 0.014 \\
\hline Gender & & & 0.159 & & & 0.075 \\
\hline Male n(\%) & 79 (54.9) & $52(46.0)$ & & $53(54.1)$ & $26(56.5)$ & \\
\hline $\begin{array}{l}\text { Female } \\
\mathrm{n}(\%)\end{array}$ & $65(45.1)$ & $61(54.0)$ & & $45(45.9)$ & $20(43.5)$ & \\
\hline AST (UI/I) & $\begin{array}{l}52.944 \pm \\
30.352\end{array}$ & $\begin{array}{l}50.575 \pm \\
35.833\end{array}$ & 0.262 & $\begin{array}{l}56.591 \pm \\
31.500\end{array}$ & $\begin{array}{l}45.174 \pm \\
26.421\end{array}$ & 0.035 \\
\hline ALT (UI/I) & $\begin{array}{l}31.458 \pm \\
18.987\end{array}$ & $\begin{array}{l}30.832 \pm \\
32.638\end{array}$ & 0.442 & $\begin{array}{l}32.800 \pm \\
21.471\end{array}$ & $\begin{array}{l}28.609 \pm \\
11.816\end{array}$ & 0.218 \\
\hline GGT (UI/I) & $\begin{array}{l}31.479 \pm \\
25.966\end{array}$ & $\begin{array}{l}25.319 \pm \\
45.375\end{array}$ & 0.924 & $\begin{array}{l}31.898 \pm \\
21.287\end{array}$ & $\begin{array}{l}30.587 \pm \\
34.126\end{array}$ & 0.779 \\
\hline $\operatorname{TP}(\mathrm{g} / \mathrm{l})$ & $\begin{array}{l}63.217 \pm \\
7.428\end{array}$ & $\begin{array}{l}69.133 \pm \\
8.352\end{array}$ & 0.604 & $\begin{array}{l}63.462 \pm \\
6.522\end{array}$ & $\begin{array}{l}62.694 \pm \\
9.123\end{array}$ & 0.564 \\
\hline ALB (g/l) & $\begin{array}{l}41.522 \pm \\
5.553\end{array}$ & $\begin{array}{l}42.412 \pm \\
6.390\end{array}$ & 0.083 & $\begin{array}{l}41.241 \pm \\
4.783\end{array}$ & $\begin{array}{l}42.120 \pm \\
6.941\end{array}$ & 0.378 \\
\hline $\begin{array}{l}\text { TBIL }(\mu \\
\mathrm{mol} / \mathrm{l})\end{array}$ & $\begin{array}{l}17.172 \pm \\
14.139\end{array}$ & $\begin{array}{l}15.988 \pm \\
22.637\end{array}$ & 0.897 & $\begin{array}{l}18.534 \pm \\
14.287\end{array}$ & $\begin{array}{l}14.272 \pm \\
13.516\end{array}$ & 0.092 \\
\hline \multicolumn{7}{|c|}{$\begin{array}{l}\text { Group T: hepatic mass group, Group C: extrahepatic abdominal mass group, Group } \mathrm{T}_{\mathrm{HB}} \text { : } \\
\text { hepatoblastoma group, Group } \mathrm{T}_{\mathrm{HE}} \text { : hemangioendothelioma group. AST: aspartate amino transferase, } \\
\text { ALT: alanine amino transferase, GGT: gamma-glutamyl transpeptidase, TP: total protein,ALB: } \\
\text { albumin, TBIL: total bilirubin. }\end{array}$} \\
\hline
\end{tabular}

\section{Serum Levels Of Pivka-ii And Afp}

Serum PIVKA-II and AFP levels were compared between the patients in the hepatic mass group and the patients in the control group and between the patients in the hepatoblastoma group and the patients in the hemangioendothelioma group. The mean level of PIVKA-II in Group T was 717.687 \pm 3026.936 $\mathrm{mAU} / \mathrm{mL}$, which was significantly higher than that of Group C $(29.954 \pm 24.924 \mathrm{mAU} / \mathrm{mL}, P=0.001)$ (Fig. 1A). The mean level of AFP in Group T was significantly higher than that in Group C (6982.617 \pm $17833.972 \mathrm{ng} / \mathrm{mL}$ vs $226.368 \pm 772.413 \mathrm{ng} / \mathrm{mL}$, Pख0.001) (Fig. 1B). 
A similar trend was found in serum PIVKA-II and AFP levels between Group $T_{H B}$ and Group $T_{H E}$. Serum levels of PIVKA-II and AFP were both significantly higher in Group $\mathrm{T}_{\mathrm{HB}}$ than Group $\mathrm{T}_{\mathrm{HE}}$ (PIVKA-II: $1025.091 \pm 3634.021 \mathrm{mAU} / \mathrm{mL}$ vs $62.467 \pm 68.900 \mathrm{mAU} / \mathrm{mL}, P=0.018 ;$ AFP: $9504.202 \pm 21023.325$ $\mathrm{ng} / \mathrm{mL}$ vs $1610.545 \pm 3825.377 \mathrm{ng} / \mathrm{mL}, P=0.013$ ) (Fig. 1C, 1D).

\section{Diagnostic values of PIVKA-Il and AFP in childhood hepatic tumor patients}

To evaluate the diagnostic value of PIVKA-II and AFP in childhood hepatic tumor patients, ROC curves were plotted to identify the cutoff values that would best differentiate hepatic tumor patients from controls. The area under the ROC curve (AUROC) of PIVKA-II was 0.867 (95\% Cl 0.822-0.911, $P<0.001$ ), and the AUROC of AFP was 0.857 ( $95 \% \mathrm{Cl} 0.808-0.906, P<0.001)$. The optimal cutoff value of PIVKA-II was $32.6 \mathrm{mAU} / \mathrm{ml}$, the sensitivity was $86.7 \%$, and the specificity was $81.3 \%$. The optimal cutoff value of AFP was $120 \mathrm{ng} / \mathrm{ml}$, the sensitivity was $84.1 \%$, and the specificity was $81.9 \%$. Serum levels of PIVKA-II and AFP were then combined to obtain a new marker for childhood hepatic tumor diagnosis. ROC analysis showed that PIVKA-II + AFP further increased the diagnostic efficiency. The AUROC was 0.891 (95\% $\mathrm{Cl} 0.850-0.933)$, higher than that of PIVKA-II or AFP alone. The combined sensitivity and specificity were $88.5 \%$ and $84.7 \%$, respectively (Fig. $2 \mathrm{~A}$ ).

\section{Differential diagnostic values of PIVKA-II and AFP in hepatoblastoma patients}

To further assess the diagnostic value of PIVKA-II and AFP levels in differentiating hepatoblastoma patients from hemangioendothelioma patients, another ROC curve was constructed. The AUROC of PIVKA-II was $0.876(95 \% \mathrm{Cl} 0.818-0.934, \mathrm{P}<0.001)$, and the AUROC of AFP was $0.743(95 \% \mathrm{Cl} 0.651-$ $0.835, \mathrm{P}<0.001)$. The optimal cutoff value of PIVKA-II was $47.1 \mathrm{mAU} / \mathrm{ml}$, sensitivity was $71.7 \%$ and specificity was $88.7 \%$. The optimal cutoff value of AFP was $560 \mathrm{ng} / \mathrm{ml}$, sensitivity was $63.0 \%$ and specificity was $78.6 \%$. ROC analysis showed that PIVKA-II + AFP further increased the differential diagnostic efficiency. The AUROC was 0.895 (95\% $\mathrm{Cl} 0.841-0.948)$, which was higher than that of PIVKAII or AFP alone. The combined sensitivity and specificity were $72.7 \%$ and $91.8 \%$ (Fig. 2B).

\section{Discussion}

Regular monitoring and an early diagnosis of childhood tumors can improve the clinical course and treatment response, which ultimately improves long-term outcomes (19). The blood tumor markers that are described in this study can be considered good indicators and can provide an acceptable diagnostic accuracy and are convenient and cost-effective.

The results of this study showed that hepatic tumor patients had significantly higher serum levels of PIVKA-II and AFP than extrahepatic abdominal tumor patients.

Prothrombin glutamate carboxylation in the liver gives rise to normal prothrombin, which contains 10carboxylic glutamate residues. The process depends on the presence of vitamin $\mathrm{K}$. In pathological states 
when vitamin $\mathrm{K}$ is too low or in the presence of a vitamin $\mathrm{K}$-dependent antagonist of carboxylase, the insufficient carboxylation of glutamic acid results in the production of PIVKA-II(20).

Motohara K. et al. reported that vitamin $\mathrm{K}$ treatment in two hepatoblastoma patients resulted in only a moderate reduction in PIVKA-II levels. An immunohistochemical study of liver tissue showed the presence of PIVKA-II in hepatoblastoma cells (9). Maha F. et al. reported similar outcomes; after vitamin K administration, PIVKA-II levels decreased in both the chronic hepatitis group $(P=0.022)$ and the cirrhosis group $(P=0.024)$ but not in the HCC group $(P=0.187)(21)$. These findings suggested that the elevation of PIVKA-II in patients with liver tumors was not due to deficiency in the nutrient vitamin $\mathrm{K}$ but due to the overproduction of PIVKA-II in tumor cells.

The subgroup analysis showed that PIVKA-II and AFP levels in patients with malignant hepatoblastoma were higher than those in patients with the benign tumor, hemangioendothelioma, in our study.

Imamura et al. reported that serum PIVKA-II levels were significantly elevated in patients with more aggressive tumor characteristics (22). Recently, many studies have demonstrated that elevated serum PIVKA-II is related to larger tumor size, more frequent vascular invasion, more intrahepatic metastasis, and recurrence after treatment(23).

A couple of previous studies reported that the optimal cutoff value of serum PIVKA-II for HCC diagnosis was estimated to range from 30 to $42 \mathrm{mAU} / \mathrm{ml}(24)$. The ROC curve analysis showed that the optimal cutoff value of PIVKA-II for the diagnosis of childhood hepatic tumors was $32.6 \mathrm{mAU} / \mathrm{ml}$ and that for differentiating hepatoblastoma from hemangioendothelioma was $47.1 \mathrm{mAU} / \mathrm{ml}$. The cutoff values of serum PIVKA-II for the diagnosis of hepatic tumors in children and adults were similar and were not affected by age.

In previous studies, the sensitivity of PIVKA-II in the diagnosis of HCC was $51.0 \%-77 \%$, the specificity was $67.8 \%-91.2 \%$, and the AUROC was $0.701-0.854$, all of which were higher than the sensitivity, specificity, and the AUROC of AFP $(17,25,26)$. In our study, the sensitivity, specificity and AUROC of PIVKA-II in the diagnosis of childhood hepatic tumors and in the differentiation of hepatoblastoma from benign hepatic tumors were all higher than AFP. PIVKA-II is a good marker with good sensitivity and specificity in the diagnosis of hepatic tumors in both children and adults.

Serum PIVKAll and AFP are produced through different mechanisms. AFP secretion in HCC results from a reexpression of a fetal antigen in the tumor, and PIVKA-II results from an independently acquired posttranslational defect in protein processing(27). Therefore, the two markers are independent from each other in the diagnosis of hepatic tumors(28). A few studies reported that PIVKA-II combined with AFP had great advantages as a biomarker for HCC screening $(29,30)$. The maximum AUROC was 0.846 , which was higher than that of PIVKA-II or AFP alone(31). We further evaluated the diagnostic performance of the combination of the two markers. The results showed that the combination of PIVKA-II and AFP further increase the efficiency for the diagnosis of childhood hepatic tumors (AUROC $=0.891$ ) and for the 
differentiation of hepatoblastoma from benign hepatic tumors (AUROC $=0.895$ ). Our study was broadly consistent with these findings.

\section{Conclusion}

This study demonstrated that the serum level of PIVKA-II was significantly higher in childhood patients with hepatic tumors, especially in those with malignant tumors. As a biomarker, PIVKA-Il had superior sensitivity and specificity in the diagnosis of hepatic tumors, and its cutoff value was not affected by age. The combination of PIVKA-II with AFP further increased the diagnostic performance. Therefore, serum PIVKA-II combined with AFP levels may be considered a screening marker for the clinical diagnosis of childhood hepatic tumors.

\section{Abbreviations}

PIVKA-II

protein induced by vitamin $\mathrm{K}$ antagonist-Il; AFP:a-fetoprotein; ROC:receiver operating characteristics; AUROC:area under the curve; HB:hepatoblastoma; HE:hemangioendothelioma; CECT:contrast-enhanced computed tomography; DCP:des-ү-carboxyprothrombin; HCC:hepatocellular carcinoma; JSH:Japan Society of Hepatology; SIOPEL:International Childhood Liver Tumors Strategy Group; CLEIA:chemiluminescence enzyme immunoassay.

\section{Declarations}

\section{Ethics approval and consent to participate.}

This study was approved by the Institutional Review Board of the Shanghai Children's Medical Center affiliated with the Shanghai Jiao Tong University of Medicine (SCMCIRB-K2017027). All patients' parents/guardians provided written informed consent.

\section{Consent for publication}

Not applicable.

\section{Competing interests}

None declared.

Funding Project of Shanghai Science and Technology Committee (17441903200ه17411950402);Science and Technology Development Fund of Shanghai Pudong New Area『PKJ2017-Y04『; Medium-and longterm clinical research project (3311 project) of Shanghai Children's Medical Center (SCMC)(ZCQSCMC2018-6); National Natural Science Foundation of China $₫ 81871727 \rrbracket$ Joint project of Pudong New Area Municipal Health Commission of ShanghaiखPW2019D-10冈Q National Natural Science Foundation of 
China $₫ 82072375 \mathbb{}$ Science and Technology Development Fund of Pudong New Area of Shanghai 『PKJ2019-Y11凹.

Authors' Contributions H.G., M.X., S.G. conceived of and designed the study. R.D., S.W., Y.F., Y.W., X.Z., X.L., Y.L. and W.L. made substantial contributions to study design. H.G., C.X., R.D., S.W., Y.F., Y.W., X.Z., X.L., Y.L. and W.L. were responsible for collecting data. J.W., J.M. Y.Z. and Q.P. were responsible for laboratory measurement. S.L. and L.X. provided statistical support. H.G. and C.X. drafted the manuscript. All authors were involved in critically reviewing the manuscript, and all gave final approval of the version to be published.

\section{Acknowledgments}

We would like to thank the study participants.

\section{Consent for publication}

Not applicable

\section{Availability of data and materials}

All data generated or analyzed during this study are included in this published article.

\section{References}

1. Brown J, Perilongo G, Shafford E, Keeling J, Pritchard J, Brock P, et al. Pretreatment prognostic factors for children with hepatoblastoma- results from the International Society of Paediatric Oncology (SIOP) study SIOPEL 1. European journal of cancer. 2000;36(11):1418-25.

2. Isaacs H. Jr. Fetal and neonatal hepatic tumors. Journal of pediatric surgery. 2007;42(11):1797-803.

3. Lazarevic V, Gaia N, Girard M, Leo S, Cherkaoui A, Renzi G, et al. When Bacterial Culture Fails, Metagenomics Can Help: A Case of Chronic Hepatic Brucelloma Assessed by Next-Generation Sequencing. Frontiers in microbiology. 2018;9:1566.

4. Baheti AD, Luana Stanescu A, Li N, Chapman T. Contrast-enhanced CT features of hepatoblastoma: Can we predict histopathology? Clinical imaging. 2017;44:33-7.

5. Li J, Wang J, Duan Y, Wang H, Dong C, Xu W. Comparison between infantile hepatic hemangioendothelioma and hepatoblastoma in pediatric patients: clinical manifestations and contrast-enhanced computed tomography features. Minerva pediatrica. 2018;70(5):497-8.

6. Finegold MJ, Lopez-Terrada DH, Bowen J, Washington MK, Qualman SJ. College of American P. Protocol for the examination of specimens from pediatric patients with hepatoblastoma. Arch Pathol Lab Med. 2007;131(4):520-9.

7. Musick SR, Babiker HM. Cancer, Hepatoblastoma. StatPearls. Treasure Island (FL)2019. 
8. Liebman HA, Furie BC, Tong MJ, Blanchard RA, Lo KJ, Lee SD, et al. Des-gamma-carboxy (abnormal) prothrombin as a serum marker of primary hepatocellular carcinoma. N Engl J Med. 1984;310(22):1427-31.

9. Motohara K, Endo F, Matsuda I, Iwamasa T. Acarboxy prothrombin (PIVKA-II) as a marker of hepatoblastoma in infants. J Pediatr Gastroenterol Nutr. 1987;6(1):42-5.

10. Fujiyama S, Morishita T, Hashiguchi $\mathrm{O}$, Sato T. Plasma abnormal prothrombin (des-gamma-carboxy prothrombin) as a marker of hepatocellular carcinoma. Cancer. 1988;61(8):1621-8.

11. Zinkin NT, Grall F, Bhaskar K, Otu HH, Spentzos D, Kalmowitz B, et al. Serum proteomics and biomarkers in hepatocellular carcinoma and chronic liver disease. Clinical cancer research: an official journal of the American Association for Cancer Research. 2008;14(2):470-7.

12. Kudo M, Izumi N, Kokudo N, Matsui O, Sakamoto M, Nakashima O, et al. Management of hepatocellular carcinoma in Japan: Consensus-Based Clinical Practice Guidelines proposed by the Japan Society of Hepatology (JSH) 2010 updated version. Digestive diseases. 2011;29(3):339-64.

13. Lim TS, Kim DY, Han KH, Kim HS, Shin SH, Jung KS, et al. Combined use of AFP, PIVKA-II, and AFP-L3 as tumor markers enhances diagnostic accuracy for hepatocellular carcinoma in cirrhotic patients. Scand J Gastroenterol. 2016;51(3):344-53.

14. Park H, Kim SU, Park JY, Kim DY, Ahn SH, Chon CY, et al. Clinical usefulness of double biomarkers AFP and PIVKA-II for subdividing prognostic groups in locally advanced hepatocellular carcinoma. Liver international: official journal of the International Association for the Study of the Liver. 2014;34(2):313-21.

15. Katzenstein HM, Langham MR, Malogolowkin MH, Krailo MD, Towbin AJ, McCarville MB, et al. Minimal adjuvant chemotherapy for children with hepatoblastoma resected at diagnosis (AHEP0731): a Children's Oncology Group, multicentre, phase 3 trial. The Lancet Oncology. 2019;20(5):719-27.

16. Gentile I, Buonomo AR, Scotto R, Zappulo E, Carriero C, Piccirillo M, et al. Diagnostic Accuracy of PIVKA-II, Alpha-Fetoprotein and a Combination of both in Diagnosis of Hepatocellular Carcinoma in Patients Affected by Chronic HCV Infection. In vivo. 2017;31(4):695-700.

17. Pote N, Cauchy F, Albuquerque M, Voitot H, Belghiti J, Castera L, et al. Performance of PIVKA-II for early hepatocellular carcinoma diagnosis and prediction of microvascular invasion. Journal of hepatology. 2015;62(4):848-54.

18. Busweiler LA, Wijnen MH, Wilde JC, Sieders E, Terwisscha van Scheltinga SE, van Heurn LW, et al. Surgical treatment of childhood hepatoblastoma in the Netherlands (1990-2013). Pediatr Surg Int. 2017;33(1):23-31.

19. Zhang SK, Sun XB. Achievements and challenges for childhood cancer in China. Annals of translational medicine. 2015;3(22):366.

20. Liebman HA. Isolation and characterization of a hepatoma-associated abnormal (des-gammacarboxy)prothrombin. Cancer research. 1989;49(23):6493-7. 
21. Saja MF, Abdo AA, Sanai FM, Shaikh SA, Gader AG. The coagulopathy of liver disease: does vitamin $\mathrm{K}$ help? Blood coagulation \& fibrinolysis: an international journal in haemostasis and thrombosis. 2013;24(1):10-7.

22. Imamura H, Matsuyama $Y$, Miyagawa $Y$, Ishida $K$, Shimada R, Miyagawa S, et al. Prognostic significance of anatomical resection and des-gamma-carboxy prothrombin in patients with hepatocellular carcinoma. Br J Surg. 1999;86(8):1032-8.

23. Park H, Park JY. Clinical significance of AFP and PIVKA-II responses for monitoring treatment outcomes and predicting prognosis in patients with hepatocellular carcinoma. BioMed research international. 2013;2013:310427.

24. Wang BL, Tan QW, Gao XH, Wu J, Guo W. Elevated PIVKA-II is associated with early recurrence and poor prognosis in BCLC 0-A hepatocellular carcinomas. Asian Pacific journal of cancer prevention: APJCP. 2014;15(16):6673-8.

25. Jang ES, Jeong SH, Kim JW, Choi YS, Leissner P, Brechot C. Diagnostic Performance of AlphaFetoprotein, Protein Induced by Vitamin K Absence, Osteopontin, Dickkopf-1 and Its Combinations for Hepatocellular Carcinoma. PloS one. 2016;11(3):e0151069.

26. Li C, Zhang Z, Zhang P, Liu J. Diagnostic accuracy of des-gamma-carboxy prothrombin versus alphafetoprotein for hepatocellular carcinoma: A systematic review. Hepatology research: the official journal of the Japan Society of Hepatology. 2014;44(10):E11-25.

27. Weitz IC, Liebman HA. Des-gamma-carboxy (abnormal) prothrombin and hepatocellular carcinoma: a critical review. Hepatology. 1993;18(4):990-7.

28. Lefrere JJ, Armengaud D, Leclerq M, Guillaumont M, Gozin D, Alagille D. Des-gammacarboxyprothrombin and hepatoblastoma. J Clin Pathol. 1988;41(3):356.

29. Viggiani V, Palombi S, Gennarini G, D'Ettorre G, De Vito C, Angeloni A, et al. Protein induced by vitamin $\mathrm{K}$ absence or antagonist-II (PIVKA-II) specifically increased in Italian hepatocellular carcinoma patients. Scand J Gastroenterol. 2016;51(10):1257-62.

30. Ertle JM, Heider D, Wichert M, Keller B, Kueper R, Hilgard P, et al. A combination of alpha-fetoprotein and des-gamma-carboxy prothrombin is superior in detection of hepatocellular carcinoma. Digestion. 2013;87(2):121-31.

31. Yu R, Ding S, Tan W, Tan S, Tan Z, Xiang S, et al. Performance of Protein Induced by Vitamin K Absence or Antagonist-II (PIVKA-II) for Hepatocellular Carcinoma Screening in Chinese Population. Hepatitis monthly. 2015;15(7):e28806.

\section{Figures}


A

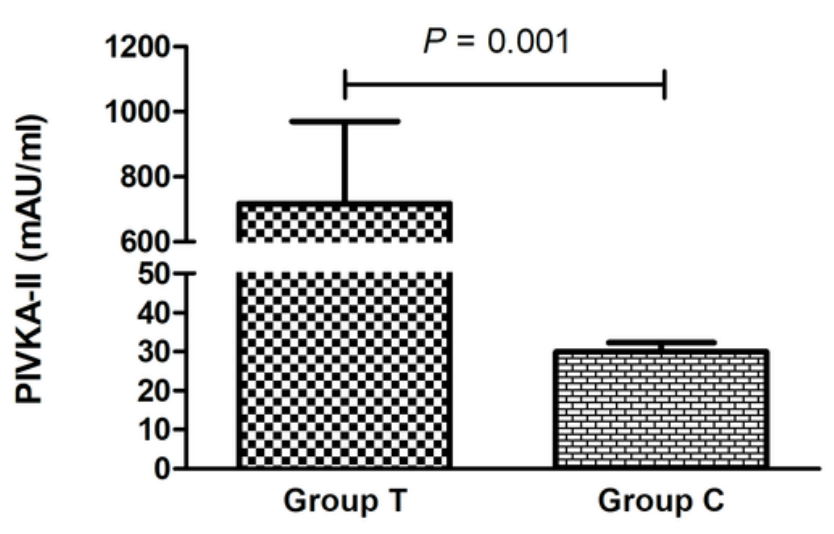

C

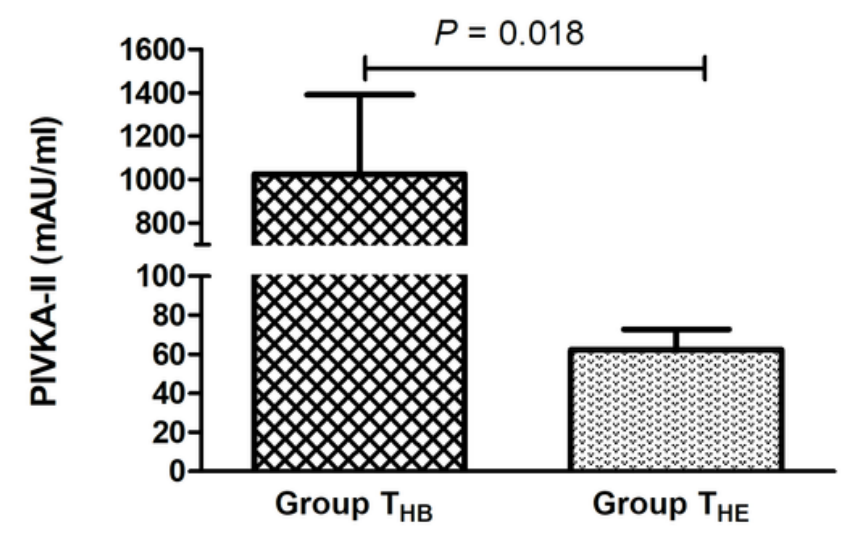

B
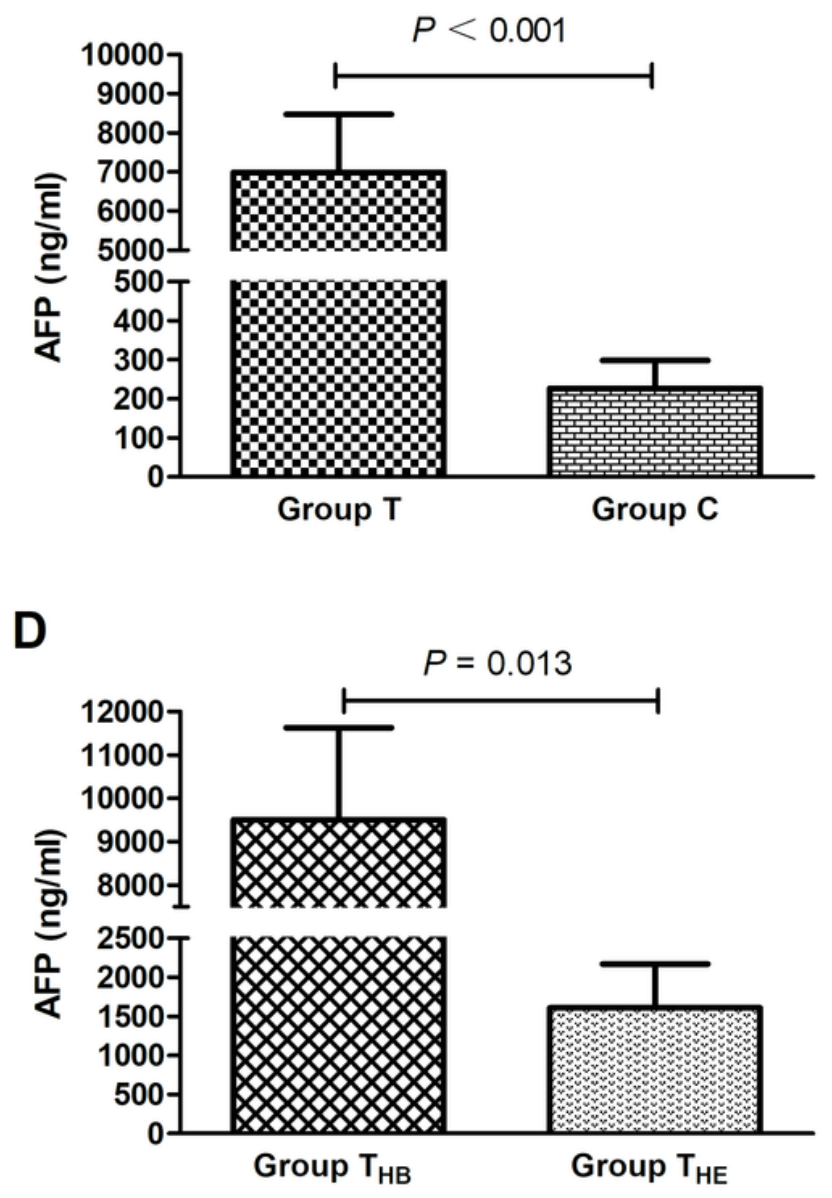

Figure 1

Serum levels of PIVKA-II and AFP. (A, B) Serum PIVKA-II and AFP levels in Group T and Group C patients; (C, D) Serum PIVKA-II and AFP levels in Group THB and Group THE patients. PIVKA-Il: protein induced by vitamin K absence-II, AFP: alpha-fetoprotein. Group T: hepatic mass group, Group C: extrahepatic abdominal mass group, Group THB: hepatoblastoma group, Group THE: hemangioendothelioma group. 
A

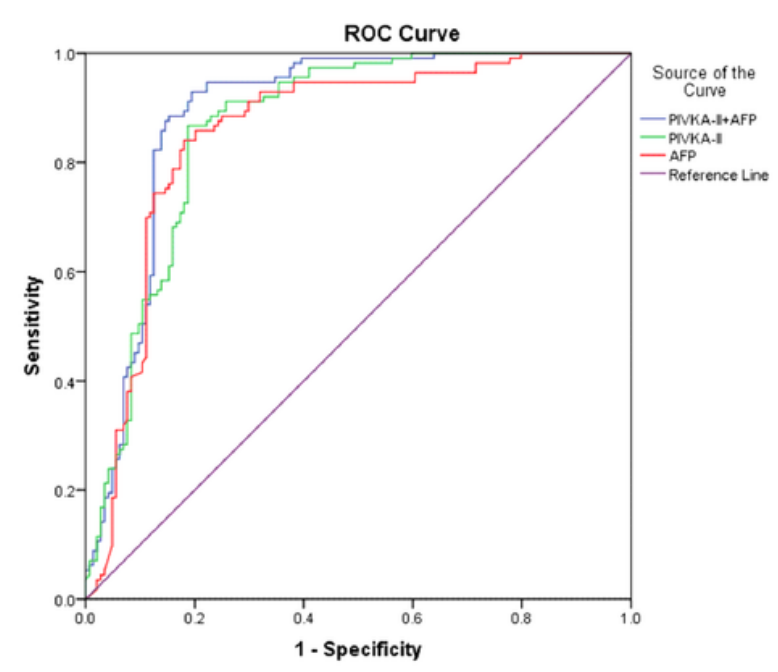

B

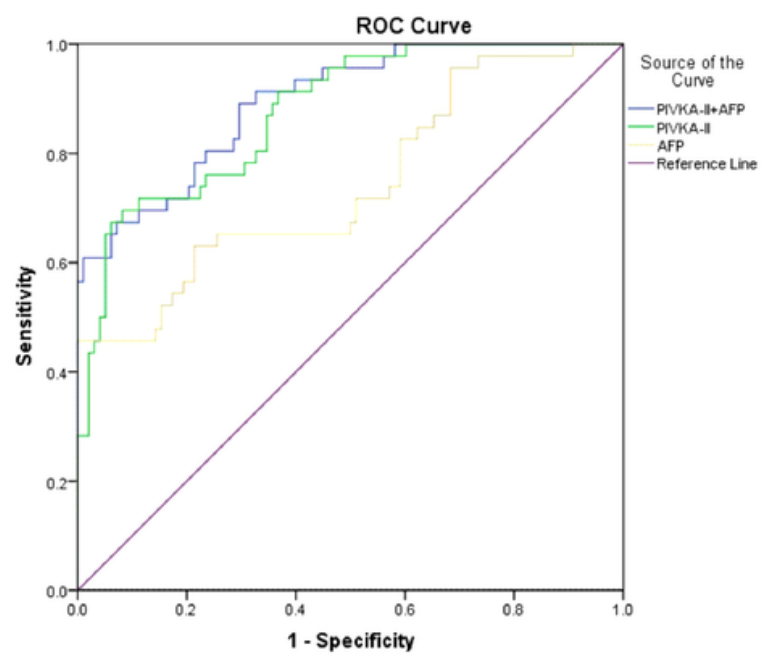

\section{Figure 2}

Diagnostic values of PIVKA-II and AFP in childhood hepatic tumor patients. A The AUROCs of PIVKA-II, AFP and PIVKA-II + AFP for the diagnosis of hepatic tumors were $0.867,0.857$ and 0.891 , respectively. B The AUROCs of PIVKA-II, AFP and PIVKA-II + AFP to differentiate hepatoblastoma from hemangioendothelioma patients were $0.876,0.743$ and 0.895 , respectively. PIVKA-II: protein induced by vitamin K absence-II, AFP: alpha-fetoprotein. 